\title{
PENDAMPINGAN PEMBUATAN ARTIKEL PTK BAGI GURU IPA KOTA PROBOLINGGO
}

\author{
Oleh: \\ Beni Setiawan ${ }^{1}$, Wahono Widodo², Dyah Astriani3 \\ 1,2,3 Jurusan IPA, FMIPA-Universitas Negeri Surabaya \\ 1benisetiawan@unesa.ac.id
}

\begin{abstract}
Abstrak
Tujuan dari pengabdian ini adalah pendampingan kepada para guru IPA dalam wadah MGMP IPA Kota Probolinggo agar mereka dapat menyusun suatu karya tulis ilmiah berupa PTK yang dapat terpublikasi pada jurnal ilmiah yang diterbitkan oleh Dinas Pendidikan Kota Probolinggo atau jurnal ilmiah lain untuk peningkatan kualitas pembelajaran serta dapat digunakan sebagai salah satu syarat kenaikan pangkat guru sesuai dengan Permennegpan dan RB No. 16 Tahun 2009 sebagai unsur pengembangan diri. Solusi yang ditawarkan dari pemasalahan di atas berupa pendampingan penulisan karya tulis ilmiah berupa PTK yang didampingi sampai pada diterimanya dalam jurnal Dinas Pendidikan atau jurnal perguruan tinggi. Hasil yang telah didapat adalah Karya Tulis IImiah berupa PTK yang akan terpublikasi pada jurnal Dinas Pendidikan Kota Probolinggo atau jurnal Nasional, yang sampai pada pendampingan terakhir sudah ada enam draft judul artikel yang berpotensi untuk dipublikasikan. Beberapa kendala yang dihadapi dalam pelaksanaan pendampingan adalah: 1) jadwal pendampingan berbenturan dengan jadwal sekolah seperti jadwal MGMP sendiri yang merupakan hari efektif, UTS, dan ujian sekolah, 2) jadwal pendampingan yang dilaksanakan berbenturan dengan jadwal dari Dinas Pendidikan setempat yang mendadak seperti pelibatan guru dalam implementasi kurikulum 2013 (IN-ON) serta persiapan sekolah contoh kurikulum 2013 dan persiapan sekolah Adiwiyata.
\end{abstract}

Kata Kunci: Pendampingan pembuatan artikel, PTK, Guru IPA

\begin{abstract}
The aim of the service is the assistance to the science teachers joining in MGMPS IPA Probolinggo city to formulate a scientific paper resulted from action research, which can be published in a scientific journal of Probolinggo Education Department or other scientific journals. The publication was to improve the quality of learning and can be used to fulfil a condition of promotion of teachers according to Permennegpan and RB No. 16 of 2009 as an element of personal development. The solution offered from above in the form of mentoring pemasalahan writing scientific papers in the form of PTK was accompanied to the Department of Education receives in journals or journals college. The results obtained are scientific paper published in the journal of Probolinggo Education Department or other national scientific journals. There were six potential drafts produced by the teacher. Some of the obstacles encountered in the implementation of the assistance are: 1) a timetable for assistance was in conflict with school schedules such as schedules MGMPs itself was an effective days, UTS, and school examinations, 2) the schedule of assistance was also clash with the schedule of the Education Department such sudden involvement of teachers in 2013 Curriculum implementation (IN-ON), the preparation of exemplary schools for 2013 Curriculum, and the preparation of Adiwiyata schools.
\end{abstract}

Keywords: writing article assistance, action research, science teacher

\section{PENDAHULUAN}

KepMenNegPan No. 84 tahun 1993 tentang jabatan fungsional guru dan angka kreditnya, menyebutkan bahwa para guru minimal golongan IVa diwajibkan untuk menulis suatu karya tulis ilmiah selain pengajaran sebagai tugas utama guru dalam syarat pengajuan kenaikan pangkat dengan jumlah angka kredit 12, akan tetapi sejak dikeluarkan Permennegpan dan RB No. 16
Tahun 2009 tertanggal 10 November 2009, menulis sebuah karya ilmiah merupakan sebuah kebutuhan dan keharusan bagi tenaga pendidik terutama bagi para guru. Bahwa guru wajib mengikuti pengembangan keprofesian berkelanjutan setiap tahunnya, dan mulai golongan IIla dengan jumlah angka kredit yang bervariasi berdasarkan jenjang pangkat/golongannya guru wajib melakukan publikasi ilmiah dan/atau karya inovatif selain pengajaran sebagai tugas utama sebagai 
syarat dalam pengajuan kenaikan pangkat guru. Misalnya Guru Pertama, pangkat Penata Muda Tingkat I, gol ruang III/b yg akan naik jabatan/pangkat menjadi Guru Muda, pangkat Penata, gol ruang III/c, angka kredit yg dipersyaratkan utk kenaikan jabatan/ pgkt, paling sedikit 4 Angka Kredit (AK) dari subunsur publikasi ilmiah dan/atau karya inovatif, dan paling sedikit 3 Angka Kredit (AK) dari subunsur pengembangan diri.

Kebutuhan guru untuk menulis karya ilmiah berupa Penelitian Tindakan Kelas atau karya tulis lain yang menunjang pengajaran guru dalam kaitannya dengan kenaikan jabatan fungsional, membuat guru memerlukan suatu pendampingan dalam rangka pembuatan karya ilmiah tersebut. Seiring dengan Penyempurnaan KepMenNegPan No. 84 tahun 1993 tentang jabatan fungsional guru dan angka kreditnya menunjukkan bahwa hanya guru yang bergolongan IVa dikenakan aturan untuk penulisan karya ilmiah. Aturan tersebut disempurnakan menjadi PerMenNegPan dan RB No.16 Tahun 2009 yang menyatakan bahwa tidak hanya guru-guru yang bergolongan IV yang harus membuat karya ilmiah berupa PTK atau karya tulis lain yang relevan untuk pengajuan kenaikan pangkat tapi juga bagi guru bergolongan III. Hal ini sesuai dengan hasil workshop dan sosialisasi PerMenNegPan dan RB No.16 Tahun 2009 tentang jabatan fungsional guru dan angka kreditnya serta pendampingan guru SD, SMP, SMA/SMK pada tahun 2011 oleh kerjasama antara Dinas Pendidikan Kota Surabaya dan Unesa Surabaya yang bertempat di STIKOM Surabaya bahwa guruguru masih kesulitan membuat proposal PTK untuk kepentingan perbaikan di kelasnya dan pengajuan kepangkatan. Kesulitan ini disebabkan salah satunya mereka kurang bisa menganalisis dan kurang peka terhadap permasalahan di kelas serta kurang pahamnya mereka tentang PTK atau karya tulis ilmiah yang relevan. Dalam pendampingan tersebut ada guru yang sudah membuat lima proposal PTK, tetapi setelah dipresentasikan kelima proposal tersebut terdiri atas PTK dan karya tulis ilmiah yang relevan berupa penelitian terapan.

Beberapa pendampingan yang sudah dilakukan selama ini di MGMP Kota Probolinggo adalah Pendampingan penulisan karya tulis ilmiah menggunakan media Wapik (Setiawan, 2013) yang menunjukkan respon positif terhadap kegiatan penulisan karya tulis ilmiah. Pendampingan yang lain banyak dilakukan oleh pihak Dinas Pendidikan Kota Probolinggo melalui pengawas IPA MGMP IPA Kota Probolinggo serta dari pihak Kementerian Agama Kota Probolinggo melalui pengawas yang ditunjuk. Pendampingan lain berupa, sosialisasi kurikulum 2013, penyusunan lembar kerja siswa berdasarkan kurikulum 2013, penggunaan alat IPA sederhana, serta keselamatan kerja di laboratorium. Pendampingan ini dilakukan untuk meningkatkan kualitas kompetensi guru yang dapat dipakai dalam pengajuan pangkat dan golongan.

Melalui pendampingan karya tulis ilmiah dalam hal ini PTK atau karya tulis ilmiah yang relevan pada jurnal yang diterbitkan minimal oleh Dinas Pendidikan Kota Probolinggo yang disesuaikan dengan format yang ada, dikaji, dan permasalahan yang muncul selama mengajar dapat diatasi. Harapannya proses belajar mengajar dapat berjalan lebih sistematis yang akan berdampak pada peningkatan hasil belajar siswa. PTK merupakan suatu kegiatan yang dapat dilakukan secara kolaborasi untuk menyelesaikan masalah dalam pembelajaran di bawah naungan MGMP IPA Dinas Pendidikan dan Kemenag Kota Probolinggo.

Kegiatan ini juga dilatarbelakangi oleh Surat Kesepakatan Kerjasama antara MGMP IPA Kota Probolinggo dengan pihak Prodi S-1 Pendidikan IPA tertanggal 17 Maret 2015. Dimana surat tersebut keluar dari hasil rintisan beberapa tim pengabdian masyarakat yang hampir setiap tahun melakukan kegiatan pelatihan/pendampingan/workshop mulai tahun 2011 sampai 2015. Kegiatan ini dilakukan dengan salah satu tujuan yaitu peningkatan kompetensi guru sesuai dengan UU Guru dan dosen.

Undang-undang RI Nomor 14 tahun 2005 tentang Guru dan Dosen, mempersyaratkan guru untuk: (i) memiliki kualifikasi akademik minimum S1/D4, (ii) memiliki kompetensi sebagai agen pembelajaran yaitu kompetensi pedagogik, kepribadian, sosial, dan profesional; dan (iii) memiliki sertifikat pendidik. Dengan berlakunya Undangundang ini diharapkan memberikan suatu kesempatan yang tepat bagi guru untuk meningkatkan profesionalismenya melalui pelatihan, penulisan karya ilmiah, pertemuan di Kelompok Kerja Guru (KKG), dan pertemuan di Musyawarah Guru Mata Pelajaran (MGMP). Dengan demikian KKG dan MGMP memiliki peran penting dalam mendukung pengembangan profesional guru. 
Untuk mewujudkan peran KKG dan MGMP dalam pengembangan profesionalisme guru, maka peningkatan kinerja kelompok kerja guru (KKG) dan musyawarah guru mata pelajaran (MGMP) merupakan masalah yang mendesak untuk dapat direalisasikan (Direktorat profesi pendidik direktorat jenderal peningkatan mutu pendidik dan tenaga kependidikan departemen pendidikan nasional republik indonesia, 2008).

MGMP IPA Kota Probolinggo berada dalam naungan Dinas Pendidikan Kota Probolinggo dengan nama MGMP IPA Kota Probolinggo dan juga dalam naungan Kemenag Kota Probolinggo dengan nama MGMP LP Ma'arif yang masing-masing membawahi guru-guru IPA dari SMP/MTs baik negeri maupun swasta.

Hasil wawancara dengan guru anggota MGMP menunjukkan permasalahan pada pengajaran sebenarnya sangat banyak, namun tidak terungkap karena guru-guru hanya mengkomunikasikan dan mendiskusikan dengan teman-teman yang dekat, tanpa ditulis sebagai dokumen pribadi untuk dirumuskan suatu pemecahan dengan segera, bahkan guru-guru tidak ada niat menceritakan permasalahan yang dihadapi di kelas kepada orang lain, sehingga penanganan sering kali terlambat dan berakibat buruk pada sekolah. Permasalahan lain yang muncul adalah kenaikan pangkat tidak hanya unsur utama tapi unsur pendukung.

Memperhatikan hal tersebut diperlukan suatu wadah untuk keluh kesah dan pengalaman guru dalam bentuk tulisan agar kegiatan diskusi, masukan dari teman guru serumpun dapat berlangsung dengan lebih terbuka, dengan harapan permasalahan yang muncul dapat diselesaikan dengan segera dan tidak berlarut-larut.

\section{METODE PELAKSANAAN}

Metode pelaksanaan berupa pendampingan penyusunan karya tulis ilmiah berupa unsur penunjang yaitu PTK atau karya tulis ilmiah yang relevan sampai pada terpublikasi pada Jurnal minimal dari Dinas Pendidikan Kota Probolinggo atau jurnal ilmiah lainnya.

Kegiatan diawali dengan menelaah unsur pengembangan diri seperti PTK dan karya tulis ilmiah yang relevan untuk menjawab rumusan masalah pertama. Selanjutnya dilakukan sosialisasi mengenai PTK, dan pendampingan menulis PTK, tindakan perbaikan, analisis, dan pelaporan PTK.

\section{HASIL DAN PEMBAHASAN}

Hasil yang dicapai dalam kegiatan pendampingan adalah sebagai berikut:

Kegiatan pendampingan pertama adalah agenda koordinasi awal dengan sekolah mitra dan guru IPA di sekolah mitra tersebut sekaligus pembagian pada materi kompetensi dasar yang terpilih.

Dari hasil koordinasi diperoleh kesepakatan dengan guru mitra adalah sebagai berikut:

1. Telah dilakukan pendampingan terhadap guru-guru IPA anggota MGMP dan hasilnya adalah judul-judul dari para peserta guru sebagai berikut:

a. Penerapan inkuiri terbimbing untuk meningkatkan kemampuan bertanya dan inferensi

b. Penerapan TGT untuk meningkatkan motivasi belajar siswa

c. Penerapan mini pralab dalam pembelajaran untuk meningkatkan kemampuan kognitif siswa

d. Penggunaan refleksi jurnal IPA untuk meningkatkan hasil belajar siswa

e. Penerapan prinsip-prinsip DI dalam pendekatan saintifik untuk meningkatkan keterampilan komunikasi dan hasil belajar siswa

f. Penerapan pembelajaran berbasis etnosains untuk meningkatkan motivasi belajar siswa

g. Penerapan metode studi kasus untuk meningkatkan kemampuan literasi IPA

h. Penerapan TGT dengan metode permainan kartu Truth and Dare untuk meningkatkan hasil belajar siswa

i. Penerapan siklus belajar MTD untuk meningkatkan minat baca dan pemahaman konsep IPA

2. Mereview judul dari guru-guru, memberikan masukan, dan menghasilkan judul yang bisa diimplementasikan dalam PTK. Hasil dari PTK ditargetkan dapat di tulis di jurnal ilmiah

3. Guru mitra melaksanakan kegiatan pembelajaran (PTK) untuk pengambilan data sebagai cikal bakal draft tulisan artikel ilmiah.

4. Draft artikel sampai laporan ini ditulis telah terkumpul enam draft artikel, diantaranya adalah: 
Tabel 1. Daftar Artikel yang Telah Dihasilkan

\begin{tabular}{lcc}
\hline \multicolumn{1}{c}{ Judul } & Nama & Asal instansi \\
\hline $\begin{array}{l}\text { Penerapan model discoveri-jurnal IPA } \\
\text { untuk meningkatkan hasil belajar siswa }\end{array}$ & Nurhidayati, M.Pd. & SMPN 1 Kota Probolinggo \\
\hline $\begin{array}{l}\text { Penerapan siklus belajar masalah- } \\
\text { tugas-diskusi (MTD) terhadap minat } \\
\text { baca dan pemahaman konsep siswa }\end{array}$ & Karyatin, M.Pd. & SMPN 1 Kota Probolinggo \\
\hline $\begin{array}{l}\text { Penerapan model pembelajaran DI } \\
\text { dalam pendekatan scientific untuk } \\
\text { meningkatkan hasil belajar siswa }\end{array}$ & Eni Widyastuti, S.Pd. & SMPN 9 Kota Probolinggo \\
\hline $\begin{array}{l}\text { Penerapan model pembelajaran level } \\
\text { inkuri untuk meningkatkan KPS lanjut }\end{array}$ & Yuli Astuti, M.Pd. & SMPN 5 Kota Probolinggo \\
\hline $\begin{array}{l}\text { Penerapan Inkuiri Terbimbing Untuk } \\
\text { Meningkatkan Keterampilan Bertanya } \\
\text { Dan Kemampuan Inkuiri siswa }\end{array}$ & Nasihin, S.Pd. & SMPN 5 Kota Probolinggo \\
\hline $\begin{array}{l}\text { Penerapan pra lab mini untuk } \\
\text { meningkatkan pemahaman konsep } \\
\text { siswa }\end{array}$ & Nurul Istifadah, S.Pd. & SMPN 9 Kota Probolinggo \\
\hline
\end{tabular}

\section{SIMPULAN DAN SARAN}

Telah dilakukan kegiatan pendampingan terhadap guru IPA Probolinggo dalam bentuk Karya Tulis IImiah yang terpublikasi pada jurnal Dinas Pendidikan Kota Probolinggo atau jurnal Nasional (jurusan IPA Unesa) bagi guru-guru IPA Kota Probolinggo.

Beberapa saran dalam kegiatan pendampingan diperoleh (1) Pelaksanaan kegiatan hendaknya disesuaikan dengan jadwal MGMP dan sekolah, serta kegiatan dari Dinas Pendidikan setempat sehingga proses dapat berjalan secara alami. (2) kegiatan pendampingan juga perlu memperhatikan jadwal sekolah seperti beberapa pelaksanaan Ujian dari sekolah sehingga jadwal pendampingan tidak terlalu jauh antara kegiatan pendampingan satu dengan kegiatan pendampingan berikutnya, (3) perlu adanya komitmen bersama terkait dengan luaran/hasil pendampingan yang telah dilaksanakan.

\section{DAFTAR PUSTAKA}

Direktorat penelitian dan pengabdian kepada masyarakat. 2013. Panduan Pelaksanaan Penelitian dan Pengabdian Kepada Masyarakat di Perguruan Tinggi edisi IX. Direktorat Jenderal Pendidikan Tinggi: Jakarta.

Direktorat Profesi Pendidik Direktorat Jenderal Peningkatan Mutu Pendidik Dan Tenaga Kependidikan. 2008. Standar Pengembangan Kelompok Kerja Guru (Kkg) Musyawarah Guru
Mata Pelajaran (Mgmp). Departemen Pendidikan Nasional Republik Indonesia.

Kementrian Pendidikan dan Kebudayaan. 2013. Kurikulum 2013 Kompetensi Dasar Sekolah Menegah Pertama / Madrasah Tsanawiyah. Kementrian Pendidikan dan Kebudayaan: Jakarta KepMenNegPan No. 84 tahun 1993

Permendikbud nomor 104 tahun 2014 tentang Penilaian Hasil Belajar oleh Pendidik Pada Pendidikan Dasar dan Pendidikan Menengah

Permennegpan dan RB No. 16 Tahun 2009.

Setiawan, dkk. 2013. Pendampingan Penulisan Karya Tulis IImiah Pada Media Wapik (Wahana Aplikasi Pendidikan \& Informasi yang Baik) Berorientasi Pada Kurikulum 2013 Bagi Guru-Guru IPA Negeri Dan Swasta Melalui MGMP IPA Kota Probolinggo. Laporan Pengabdian Kepada Masrakat Dana BOPTN Unesa Surabaya: Prodi Pendidikan Sains FMIPA UNESA.

Setiawan B dan Asnawi. 2012. Pelatihan Guru Matematika dan IPA (MIPA) SD/MI Se-Kota Probolinggo Melalui Program BEC Kota Probolinggo. Hasil pendampingan pelatihan: Probolinggo

Setiawan, dkk. 2011. Workshop Penyusunan Perangkat Pembelajaran IPA Terpadu pada Madrasah Tsanawiyah (MTs) Negeri dan Swasta Melalui MGMP IPA Departemen Agama Kota Probolinggo. Laporan Pengabdian Kepada Masrakat Dana DIPA Unesa 
